\title{
Gold catalyzed liquid phase oxidation of alcohol: the issue of selectivity
}

\author{
L. Prati, ${ }^{* a}$ A. Villa, ${ }^{a}$ C. E. Chan-Thaw, ${ }^{a}$ R. Arrigo, ${ }^{b}$ D. Wang ${ }^{c}$ \\ and D. S. $\mathrm{Su}^{b}$
}

\author{
Received 11th February 2011, Accepted 2nd March 2011 \\ DOI: 10.1039/c1fd00016k
}

\begin{abstract}
Commercial carbon nanotubes (CNTs) and carbon nanofibers (CNFs) modified in various ways at the surface have been used as supports for gold nanoparticles (AuNPs) in order to study their influence on the activity/selectivity of catalysts in the aqueous oxidation of alcohol. Particularly oxidative treatment was used to introduce carboxylic functionalities, whereas subsequent treatment with $\mathrm{NH}_{3}$ at different temperatures $(473 \mathrm{~K}, 673 \mathrm{~K}$ and $873 \mathrm{~K})$ produced $\mathrm{N}$-containing groups leading to an enhancement of basic properties as the $\mathrm{NH}_{3}$ treatment temperature was increased. The nature of the $\mathrm{N}$-containing groups changed as the temperature increased, leading to an increase in the hydrophobicity of the support surface. Similar Au particle size and similar textural properties of the supports allowed the role of chemical surface groups in both the activity and the selectivity of the reaction of glycerol oxidation to be highlighted. An increase of basic functionalities produced a consistent increase in the activity of the catalyst, which was correlated to the promoting effect of the basic support in the alcoholate formation and the subsequent $\mathrm{C}-\mathrm{H}$ bond cleavage. The selectivity towards primary oxidation products ( $\mathrm{C} 3$ compounds) was the highest for the catalysts treated with $\mathrm{NH}_{3}$ at $873 \mathrm{~K}$, which presented the most hydrophobic surface. The same trend in the catalyst activity has been obtained in the aqueous benzyl alcohol base-free oxidation. As in the case of glycerol, the increasing of basicity and/or hydrophobicity increased the consecutive reactions.
\end{abstract}

\section{Introduction}

The success of gold as a catalyst for selective oxidation in the liquid phase is principally due to the peculiar characteristics of this metal compared to more classical Pd or Pt based catalysts when $\mathrm{O}_{2}$ is used as the oxidant. In fact, it has been shown that a Au catalyst is less prone to deactivation in the presence of $\mathrm{O}_{2}$ compared to $\mathrm{Pd}$ or Pt. ${ }^{1-3}$ Moreover, gold catalysts show high selectivity towards the oxidation of primary alcohol with respect to secondary alcohol. ${ }^{1,2}$ Since the first observation on ethylene glycol, a lot of papers have dealt with the application of gold catalysts to this important class of reaction, mainly with two aims. The first aim is to try to improve the activity and the second aim is to avoid parallel or consecutive reactions, thus enhancing the selectivity to the desired product. This latter aspect is very important from an application point of view and most recent studies focused on it. Moreover, the mechanistic understanding of the factors ruling selectivity become a priority task for optimizing catalyst design.

a Dipartimento di Chimica Inorganica Metallorganica e Analitica L. Malatesta, Università degli Studi di Milano, Via Venezian 21, 20133 Milano, Italy.E-mail: Laura.Prati@unimi.it

${ }^{b}$ Fritz Haber Institute of the Max Planck Society, Faradayweg 4-6, D-14195 Berlin, Germany

'Institut für Nanotechnologie, Forschungszentrum Karlsruhe in der Helmholtz-Gemeinschaft, Hermann-von-Helmholtz-Platz 1, 76344 Eggenstein-Leopoldshafen, Germany 
One of the most studied substrates is benzyl alcohol, which can be selectively oxidized to benzaldehyde. Dehydrogenation on gold-supported nanoparticles to produce aldehyde can be competitive with the disproportionation of benzyl alcohol to benzaldehyde and toluene, ${ }^{4}$ but dehydrogenation prevails when small gold nanoparticles $(<4 \mathrm{~nm})$ are present. This is due to the increasing of the unsaturated coordination sites, which promotes the $\beta \mathrm{C}-\mathrm{H}$ bond cleavage, which represents the rate determining step. This trend was confirmed also by periodic density functional theory (DFT) calculations ${ }^{5}$ addressing the higher activity of small nanoparticles to the roughness of the surface. High selectivity to benzaldehyde $(>99 \%)$ has been reported depending on reaction conditions, i.e. solvent, temperature, but principally on the support employed ( $\mathrm{MgO}$ and hydrotalcite). ${ }^{4}$ The main by-products are represented by benzoic acid, benzyl benzoate (from consecutive reactions) or toluene and benzene (from parallel reactions). The selectivity of the reaction can be strongly affected by the presence of a base, whose function is still under investigation. It is believed that the base can cleave the $\mathrm{O}-\mathrm{H}$ bond of the alcohol to form an alkoxide intermediate. ${ }^{6}$ In this process, the role of the support (especially at the interface with the Au nanoparticles) and also the role of coadsorbed oxygen atoms on Au surface could be relevant. ${ }^{4,7}$

Glycerol represents another well-studied substrate, in view of its importance as a cheap material derived from biomass, on which a new chemical platform can be based. ${ }^{8,9}$ Glycerol presents some fundamental differences compared to benzyl alcohol: the non-activating nature of the $\mathrm{OH}$ groups $\left(\mathrm{p} K_{\mathrm{a}}=14\right)$, the presence of primary beside secondary $\mathrm{OH}$ groups and the chelating nature (also of the oxidation products), which can strongly affect the catalyst life by providing irreversible adsorption and/or enhancing the leaching of metal. Moreover, another important difference lies in the aqueous solubility and the cheap availability of glycerol only in aqueous solution. Therefore, all the catalytic tests should be carried out in water instead of in organic solvent (toluene, xylene, cyclohexane) or solventless, as in the case of benzyl alcohol.

Since the first studies on glycerol oxidation, ${ }^{1,2}$ it appeared evident that basic conditions enhanced both activity and selectivity positively. In fact, the presence of a base enhanced the reaction rate by facilitating the alkoxide formation ${ }^{10,11}$ and by favoring

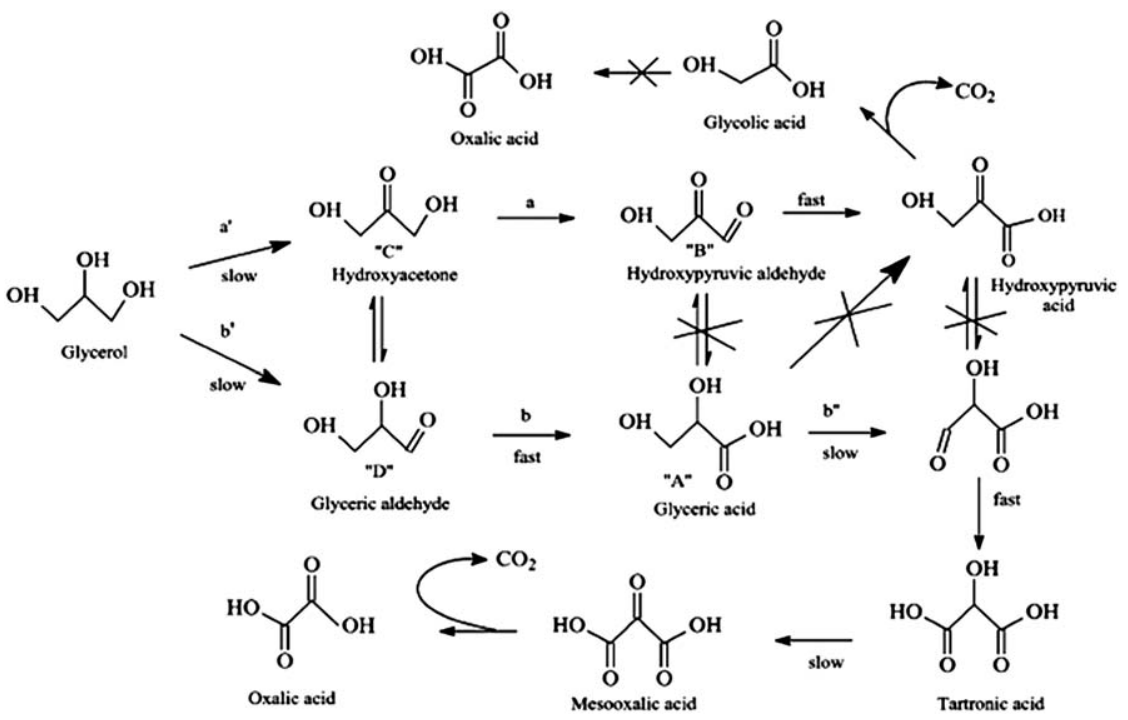

Scheme 1 Reaction scheme for glycerol oxidation under basic conditions. 
the desorption of the highly-chelating hydroxyacid, thus decreasing irreversible adsorption on metal active sites. ${ }^{12}$ In addition, basic conditions also have a beneficial effect on the selectivity towards the primary alcohol oxidation products (i.e. glycerate) (Scheme 1) through keto-enolic equilibrium and through accelerating the decomposition rate of $\mathrm{H}_{2} \mathrm{O}_{2}$ formed during the reaction, which has been recognized as responsible for the majority of the $\mathrm{C}-\mathrm{C}$ bond cleavage products (i.e. glycolate, oxalate, formate). ${ }^{10,13}$

More recently, efforts in oxidizing glycerol in a base-free medium revealed the specific role of the support, but also showed evidence of the limitation in using monometallic gold based catalysts. ${ }^{14}$ In fact, even under stronger conditions (373 $\mathrm{K})$ than those used when the base was present $(323-333 \mathrm{~K})$, the reaction rates were very low and only the addition of a second metal (typically $\mathrm{Pt}$ ) yielded a discrete reaction rate. Selectivity appeared to be determined mainly by the support. According to the model suggested by Davis, on the basis of DFT calculations and labeling tests, ${ }^{11}$ the role of the support becomes fundamental in the second elementary step of the reaction, i.e. the hydration of aldehyde to acetal with the subsequent formation of the corresponding carboxylic acid. Thus, in this study, we investigated the role of the support in the selective glycerol oxidation further, mainly focusing our attention on the selectivity of the process.

\section{Experimental}

\section{Materials}

The gold sponge, $99.9999 \%$ purity, was purchased from Fluka. Commercial CNFs PR24-PS from Applied Science (average diameter of $88 \pm 30 \mathrm{~nm}$ and a specific surface area of $43 \mathrm{~m}^{2} \mathrm{~g}^{-1}$ ) and CNTs Baytubes (average diameter of $10 \pm 2 \mathrm{~nm}$ and a specific surface area of $288 \mathrm{~m}^{2} \mathrm{~g}^{-1}$ ) from Bayer were employed. The functionalization of the CNFs and the CNTs was performed according to the procedure report in ref. 15. The oxygen-containing nanocarbons were obtained by treating the pristine support with $\mathrm{HNO}_{3}$ according to the following procedure: a solution of CNTs in $\mathrm{HNO}_{3}$ concentrate $\left(20 \mathrm{~g}\right.$ of CNT per liter of $\mathrm{HNO}_{3}$ ) was kept at 373 $\mathrm{K}$ for $2 \mathrm{~h}$ under continuous stirring, then rinsed with distilled water, and finally dried at $343 \mathrm{~K}$ for several hours. N-containing CNFs were obtained from the pre-oxidized CNFs by thermal treatment ( $10 \mathrm{~g}$ for each batch) with $\mathrm{NH}_{3}$ in the temperature range $473-873 \mathrm{~K}$ for $4 \mathrm{~h}$. $\mathrm{NaBH}_{4}$ of purity $>96 \%$ purchased from Fluka and polyvinylalcohol (PVA) (M 10,000) from Aldrich were used. $\mathrm{NaOH}$ of the highest purity available was also from Fluka. Gaseous oxygen from SIAD (99.99\% pure) was used. Glycerol (87\% wt solution), glyceric acid and all the intermediates were purchased from Fluka. Benzyl alcohol, benzaldehyde, toluene and all the intermediates were also from Fluka.

\section{Catalyst preparation}

a) PVA-protected gold sol preparation. Solid $\mathrm{NaAuCl}_{4} \cdot 2 \mathrm{H}_{2} \mathrm{O}(0.043 \mathrm{mmol})$ and PVA $(2 \% \mathrm{wt})$ solution $(1.64 \mathrm{~mL})$ were added to $130 \mathrm{~mL} \mathrm{H} \mathrm{H}_{2} \mathrm{O}$. After $3 \mathrm{~min}, \mathrm{NaBH}_{4}$ $(0.1 \mathrm{M})$ solution $(1.3 \mathrm{~mL})$ was added to the yellow solution under vigorous magnetic stirring. The ruby red $\mathrm{Au}(0)$ sol was formed immediately. ${ }^{16}$

b) Immobilization step. Within a few minutes of sol generation, the sol was immobilised by adding the support under vigorous stirring. The amount of support was calculated to have a final gold loading of $1 \%$ wt. After $2 \mathrm{~h}$, the slurry was filtered and the catalyst washed thoroughly with distilled water; it was then used in the wet form. ICP analyses were performed on the filtrate using a Jobin Yvon JV24 to verify the gold loading on the support. 


\section{Catalyst characterisation}

a) Titration procedure. Potentiometric titration of the basic sites was carried out on the samples using a Mettler Toledo Titrator. Approximately $0.2 \mathrm{~g}$ of sample was suspended in $50 \mathrm{~mL}$ of $\mathrm{KCl} 10^{-3} \mathrm{M}$ and then sonicated and equilibrated for several hours. Prior to each measurement, the suspension was continuously saturated with argon to eliminate the influence of $\mathrm{CO}_{2}$, until the $\mathrm{pH}$ was constant. Volumetric standards of $\mathrm{HCl}(0.01 \mathrm{M})$ or $\mathrm{NaOH}(0.10 \mathrm{M})$ were used as titrant, starting from the initial $\mathrm{pH}$ of the $\mathrm{CNFs}$ suspension.

b) Metal loading. The gold content for the sol prepared catalysts was checked by ICP analysis of the filtrate on a Jobin Yvon JY24. The water content was determined by drying a sample at $423 \mathrm{~K}$ in air for $5 \mathrm{~h}$. A check of Au loading was also performed directly on the catalysts, confirming the quantitative adsorption of Au NPs of the sol. The samples were weighed and loaded into a home-made $\mathrm{NaCl}$ crucible, then annealed at $973 \mathrm{~K}$ for two hours in air to burn off the carbon support. The residue was then dissolved in $5 \mathrm{~mL}$ of freshly made aqua-regia $(3: 1$ hydrochloric/nitric acid - Omnipure grade - EMD). The sample was diluted to $50 \mathrm{~mL}$ with deionized water. ICP Standards were prepared by serial dilution of an Alfa-Aesar Au ICP standard. The dissolved $\mathrm{NaCl}$ had no effect on the ICP data.

c) Morphology and microstructure of the catalysts were characterized by TEM. The powder samples of the catalysts were ultrasonically dispersed in ethanol and mounted onto copper grids covered with carbon film. A Philips CM200 FEG electron microscope, operating at $200 \mathrm{kV}$ and equipped with a Gatan Tridiem imaging filter, was used for TEM observation. EDX analysis was performed in the same microscope using a DX4 analyzer system (EDAX).

\section{Oxidation experiments}

The reactions were carried out in a thermostatted glass reactor $(30 \mathrm{~mL})$ provided with an electronically controlled magnetic stirrer connected to a large reservoir $(5000 \mathrm{~mL})$ containing oxygen at $300 \mathrm{kPa}$.

Glycerol oxidation: $0.3 \mathrm{M}$ Glycerol solution, $\mathrm{NaOH}(\mathrm{NaOH} /$ glycerol $=4 \mathrm{~mol}$ $\mathrm{mol}^{-1}$ ) and the $\mathrm{Au}$ catalyst $\left(\right.$ glycerol $/ \mathrm{metal}=1000 \mathrm{~mol} \mathrm{~mol}^{-1}$ ) were added (total volume $10 \mathrm{~mL}$ ). The reactor was pressurised at $300 \mathrm{kPa}$ of $\mathrm{O}_{2}$ and thermostatted at $323 \mathrm{~K}$. After an equilibration time of $5 \mathrm{~min}$, the reaction was initiated by stirring and samples were taken every $15 \mathrm{~min}$ and analysed by HPLC on a Varian 9010 HPLC equipped with a Varian $9050 \mathrm{UV}(210 \mathrm{~nm})$ and a Waters R.I. detector in series. An Alltech OA-1000 column $(300 \mathrm{~mm} \times 6.5 \mathrm{~mm})$ was used with aqueous $\mathrm{H}_{3} \mathrm{PO}_{4} 0.1 \% \mathrm{wt} / \mathrm{wt} \mathrm{M}\left(0.5 \mathrm{~mL} \mathrm{~min}^{-1}\right)$ as the eluent. Samples of the reaction mixture $(0.5 \mathrm{~mL})$ were diluted $(5 \mathrm{~mL})$ using the eluent. Products were assigned by comparison with authentic samples.

Base-free reactions were carried out under the same conditions except for the temperature, which was increased to $373 \mathrm{~K}$ and glycerol/metal ratio $\left(500 \mathrm{~mol} \mathrm{~mol}^{-1}\right)$

Benzyl alcohol oxidation: $0.3 \mathrm{M}$ benzyl alcohol and the catalyst (substrate/metal $=500 \mathrm{~mol} \mathrm{~mol}^{-1}$ ) were mixed in distilled water (total volume $10 \mathrm{~mL}$ ). The reactor was pressurized at the desired pressure of $\mathrm{O}_{2}$ and thermostatted at $333 \mathrm{~K}$. The reaction does not start during the heating to temperature, as verified by sampling when the reaction temperature was reached without stirring $(t=0)$. The reaction was initiated by stirring. After the end of reaction, the catalyst was filtered off and the product mixture was extracted with cyclohexane. Recoveries were always $98 \% \pm 3$ with this procedure. For the identification and analysis of the products, a GC-MS and GC (a Dani 86.10 HT Gas Chromatograph equipped with a capillary column, BP21 $30 \mathrm{~m} \times 0.53 \mathrm{~mm}, 0.5 \mu \mathrm{m}$ Film, made by SGE) were used. Comparison with authentic samples was used. For the quantification of the reactant-products, the calibration method using an external standard was employed. 


\section{Test for hydrogen peroxide degradation}

A $1 \mathrm{mM}$ solution of $\mathrm{H}_{2} \mathrm{O}_{2}(15 \mathrm{~mL})$ was stirred at the appropriate temperature under $\mathrm{N}_{2}$ atmosphere. The $\mathrm{pH}$ of the solution was adjusted by adding $\mathrm{H}_{2} \mathrm{SO}_{4} 6 \mathrm{M}(\mathrm{pH} 2)$. The amount of the catalyst added was the same as in the glycerol oxidation (about 20-30 mg). Hydrogen peroxide was quantified time by time by permanganate titration. The following procedure has been used: a sample $(5 \mathrm{~mL})$ of the filtered reacting solution was titrated with a $0.01 \mathrm{~N} \mathrm{KMnO}_{4}$ solution at constant $\mathrm{pH}$ of $2.0 \pm 0.1$ (by adding concentrated $\mathrm{H}_{2} \mathrm{SO}_{4}$ ). The detection limit of $\mathrm{H}_{2} \mathrm{O}_{2}$ was $0.01 \mathrm{mM}$.

\section{Results and discussion}

The selectivity of the reaction, as discussed above, can be strongly affected by the presence of a base. However, a relationship between particle size and selectivity was found. ${ }^{1,2}$ Larger gold particles $\left(>10 \mathrm{~nm}\right.$ ) were more selective towards $\mathrm{C}_{3}$-oxidation products than smaller ones, which produced a relevant amount of $\mathrm{C}-\mathrm{C}$ bond cleavage products. However, more recent studies revealed that selectivity could be ruled by a more complex platform of factors. ${ }^{17-19}$ Particularly the textural and chemical properties of the supporting material appeared to be fundamental. ${ }^{17}$ In fact, it was reported that selectivity in the glycerol oxidation of $\mathrm{Au}$ on $\mathrm{MgAl}_{2} \mathrm{O}_{4}$ is tuned by the $\mathrm{Al} / \mathrm{Mg}$ ratio at the surface besides the particle size and the exposure of the metal. Therefore, for studying the pure support effect in more detail, any other differences such as particle size, surface area and porosity of the supporting materials should be avoided. The selection of the materials was thus performed, taking into account the surface area (as high as possible to increase the metal dispersion) and porosity (avoiding as much as possible micropores for diffusional problems). Moreover, a surface which is easy to modify should be considered. Carbon nanotubes (CNTs) appeared to be good candidates, as they show regular textural properties with surface groups which can be modified by chemical/physical treatments without damaging the overall structure.

Two different commercial samples were used as starting materials. The characterizations have been recently reported: ${ }^{20}$ one from Bayer Material Science A.G. (Baytubes, Carbon Nanotubes CNT) and one from Pyrograf Products Inc. (PR24, Carbon Nanofiber CNF). The physical properties of these two materials are reported in Table 1. An oxidative treatment $\left(\mathrm{HNO}_{3} 65 \% \mathrm{wt}, 2 \mathrm{~h}, 373 \mathrm{~K}\right)$ increased the functionalization on the outermost walls, but did not significantly affect either the grain shape and the size, or the structure. An important effect of the treatment was, in both cases, to remove residual amorphous carbon from the surface. This procedure is known to increase the presence of carboxylic acids. ${ }^{20}$ The acidic site titration confirmed an increase of the amount of acidic groups (Table 1). A basic functionalization was carried out by the subsequent treatment with $\mathrm{NH}_{3}$ at different temperatures, following the procedure reported elsewhere. ${ }^{21}$ Table 2 reports the basic site titration data that show the increase of the basic groups with increasing post-treatment temperature $(473 \mathrm{~K}-673 \mathrm{~K}-873 \mathrm{~K})$. It should be noted that, even at the highest temperature $(873 \mathrm{~K})$, the overall structure of CNFs was maintained. ${ }^{21}$

Table 1 Physical data for CNTs and CNFs

\begin{tabular}{llllll}
\hline & $\mathrm{AS}\left(\mathrm{m}^{2} \mathrm{~g}^{-1}\right)$ & Micropore area $\left(\mathrm{m}^{2} \mathrm{~g}^{-1}\right)$ & diameter $(\mathrm{nm})$ & $\mathrm{pH}$ & mol acid sites/g \\
\hline $\mathrm{CNT}$ & $288^{a}$ & $40^{a}$ & $10 \pm 2$ & 10 & - \\
$\mathrm{CNT}$ ox & $321^{a}$ & $38^{a}$ & $10 \pm 2$ & 4.35 & $2.6 \times 10^{-3}$ \\
$\mathrm{CNF}$ & $43^{a}$ & $0^{a}$ & $88 \pm 30$ & 6.5 & - \\
$\mathrm{CNF}$ ox & $37^{a}$ & $5^{a}$ & $88 \pm 30$ & 4.52 & $4.5 \times 10^{-3}$ \\
\multicolumn{2}{l}{ From ref. [20,21]. } & & & & \\
\end{tabular}


Table 2 Titration data for N-CNFs

\begin{tabular}{lll}
\hline Sample & mol basic sites/g & Generated $\mathrm{pH}$ \\
\hline N-CNF 473 K & $4.5^{*} 10^{-4}$ & 8.0 \\
N-CNF 673 K & $6 * 10^{-4}$ & 8.2 \\
N-CNF 873 K & $1 * 10^{-3}$ & 8.5 \\
\hline
\end{tabular}

Table 3 Au particle size on CNTs and CNFs

\begin{tabular}{lllllllll}
\hline & $\begin{array}{l}\mathrm{Au} \\
\mathrm{sol}\end{array}$ & $\begin{array}{l}\mathrm{Au} / \mathrm{CNT} \\
\text { pristine }\end{array}$ & $\begin{array}{l}\mathrm{Au} / \\
\mathrm{CNT} \text { ox }\end{array}$ & $\begin{array}{l}\mathrm{Au} / \mathrm{CNF} \\
\text { pristine }\end{array}$ & $\begin{array}{l}\mathrm{Au} / \\
\mathrm{CNF} \text { ox }\end{array}$ & $\begin{array}{l}\mathrm{Au} / \mathrm{N} \\
\mathrm{CNF}\end{array}$ & $\begin{array}{l}\mathrm{Au} / \\
\mathrm{N}-\mathrm{CNF}\end{array}$ & $\begin{array}{l}\mathrm{Au} / \\
\mathrm{N}-\mathrm{CNF}\end{array}$ \\
\hline $\begin{array}{l}\text { Statistical } \\
\text { median }(\mathrm{nm})\end{array}$ & 2.45 & 4.61 & 3.83 & 3.80 & 3.65 & 3.15 & 3.11 & 2.94 \\
$\begin{array}{l}\text { Standard } \\
\text { deviation } \sigma\end{array}$ & 0.27 & 1.32 & 0.89 & 0.95 & 0.78 & 0.57 & 0.64 & 0.51 \\
\hline
\end{tabular}

CNTs and CNFs presented different surface areas, but the contribution of micropores could be considered negligible in both cases (Table 1).

We prepared thus Au supported nanoparticles (AuNPs) on CNTs and CNFs through the sol immobilization technique which represents the most suitable method for obtaining similar particle size distribution, regardless of the supporting material employed. ${ }^{16}$ The Au particle size distributions obtained are reported in Table 3. During the immobilisation step, we noticed an increase in the size of the nanoparticles, probably due to coalescence that increases with decreasing interaction strength between the AuNPs and the support surface. As preformed AuNPs are identically generated in all the cases, we can address the difference in diameter of supported AuNPs to the different surface chemical groups and in particular to their density. Indeed, we observed similar particle diameter for AuNPs immobilized on all the treated supports (about 3-4 nm) with a decreasing of the discrepancy between diameter in the sol and on the support (i.e. before and after the deposition) by increasing the functional group density.

The acidic groups, introduced by oxidative treatment, appeared less efficient in stabilizing the nanoparticle diameter than the basic groups. In fact Au/CNT ox and $\mathrm{Au} / \mathrm{CNF}$ ox showed the most remarkable increase in the Au particle diameter (3.83 and $3.65 \mathrm{~nm} v$ s. $2.94 \mathrm{~nm}$ for a comparable density of functional groups - Table 3). Pristine CNTs and CNFs lead to poor metallic dispersion, probably also due to the presence of amorphous carbon, which preferentially adsorbs the AuNPs from the sol. Some representative TEM pictures for Au/CNF and Au/CNT are shown (Fig. 1 and 2), demonstrating the increase in metal dispersion obtained after functionalization.

Regarding the activity of the catalysts, there are a lot of examples in the literature confirming that the activity of the catalysts in the liquid phase is related to the surface exposure of the active sites that should increase by decreasing the particle size. ${ }^{17,18}$ In the present case, the external functionalization of the support surface, the negligible presence of micropores and the methodology chosen for the deposition of the gold nanoparticles should avoid the limitation due to diffusion problems. We should thus expect a trend of activities which follows the particle sizes. However, looking at the reaction profiles (Fig. 3 and 4) it can be seen clearly that this expected trend was not followed. In fact, $\mathrm{Au} / \mathrm{CNT}$ ox and $\mathrm{Au} / \mathrm{CNF}$ ox, even showing a very similar particle size distribution (mean size $3.83 \mathrm{~nm} v$ s. $3.65 \mathrm{~nm}$ - Table 3), presented 
TOFs of $742 \mathrm{~h}^{-1}$ and $186 \mathrm{~h}^{-1}$, respectively (Table 4 - Fig. 3). Also, Au/N-CNF $473 \mathrm{~K}$ and $\mathrm{Au} / \mathrm{N}-\mathrm{CNF} 673 \mathrm{~K}$ with almost the same particle size $(3.15 \mathrm{~nm}$ and $3.11 \mathrm{~nm}$, respectively) showed TOFs of 112 and $597 \mathrm{~h}^{-1}$, respectively (Table 4 - Fig. 4). This definitely supports the idea that the supporting material plays an active role in determining the rate of glycerol oxidation. This is in agreement with the
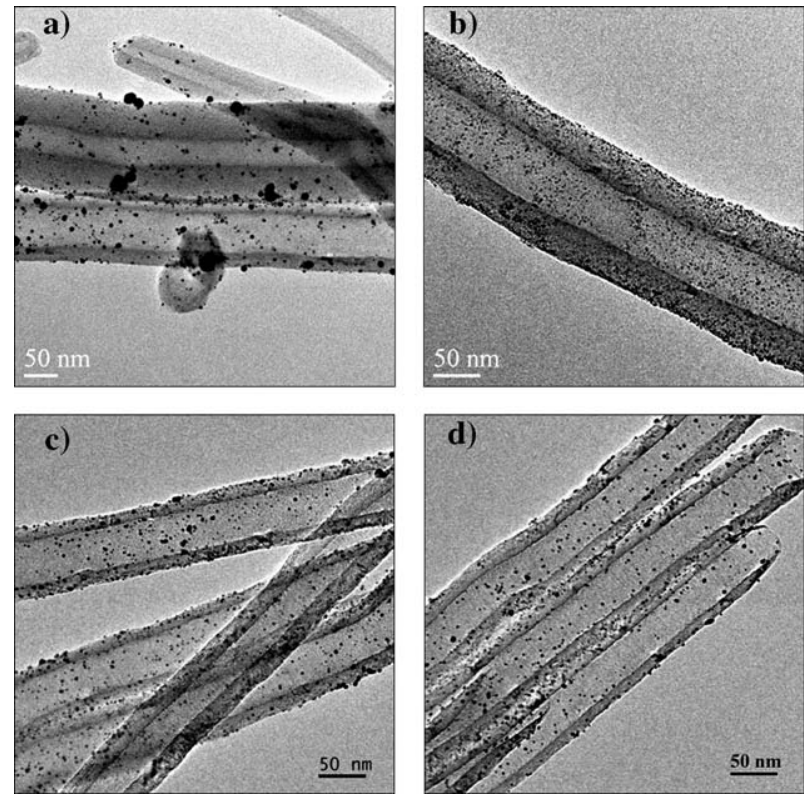

Fig. 1 TEM images of a) Au/CNF, b) Au/CNF ox, c) Au/CNT, d) Au/CNT ox.
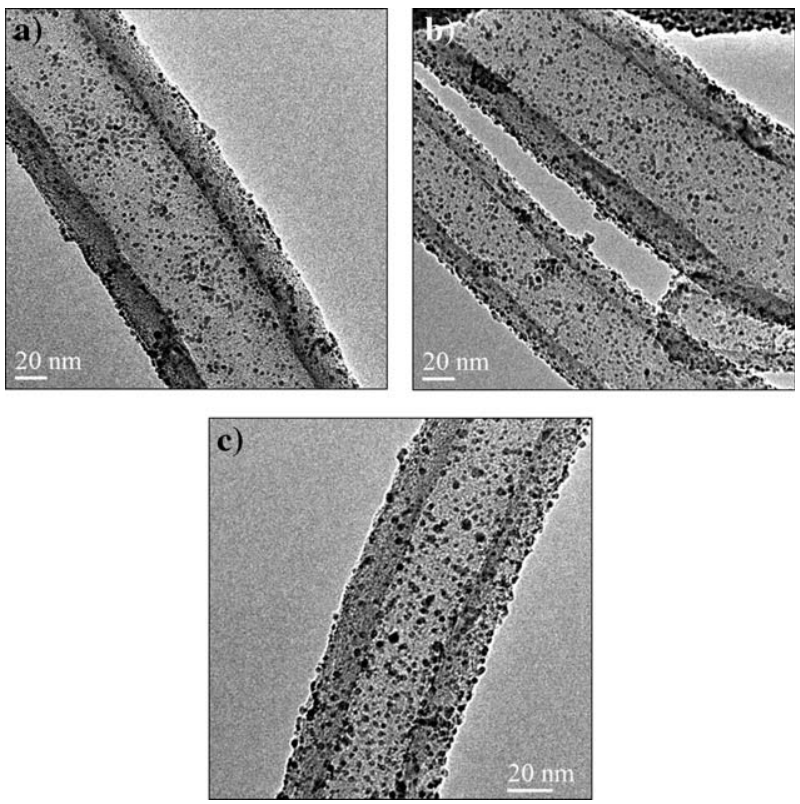

Fig. 2 TEM images of a) Au/N-CNF $473 \mathrm{~K}$, b) Au/N-CNF $673 \mathrm{~K}$, c) Au/N-CNF $873 \mathrm{~K}$. 


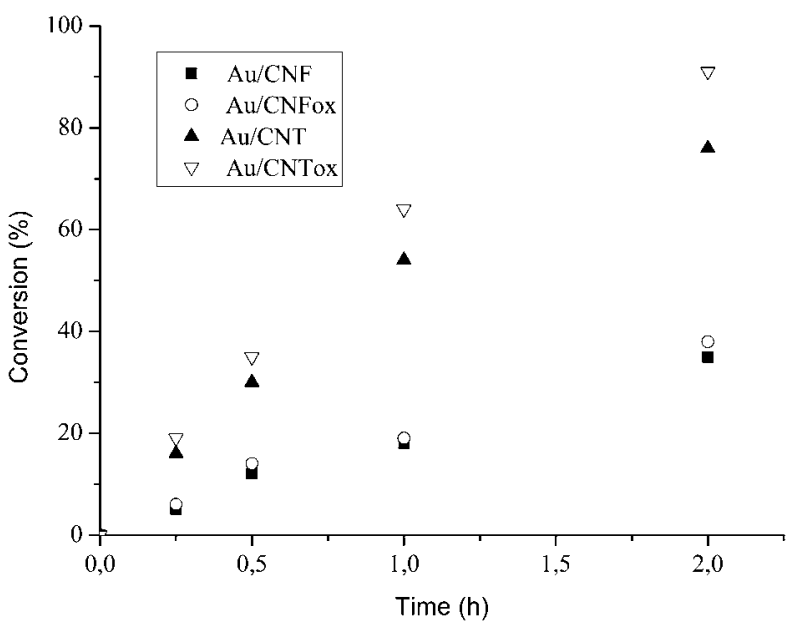

Fig. 3 Reaction profile for glycerol oxidation using $\mathrm{Au} / \mathrm{CNF}, \mathrm{Au} / \mathrm{CNT}, \mathrm{Au} / \mathrm{CNF}$ ox and $\mathrm{Au} /$ CNT ox.

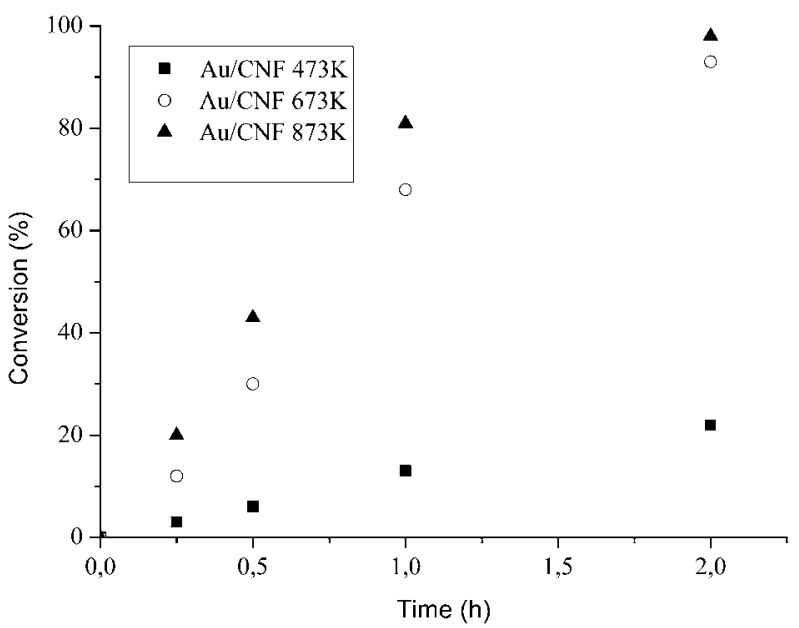

Fig. 4 Reaction profile for glycerol oxidation using Au/N-CNF $473 \mathrm{~K}, \mathrm{Au} / \mathrm{N}-\mathrm{CNF} 673 \mathrm{~K}$, $\mathrm{Au} / \mathrm{N}-\mathrm{CNF} 873 \mathrm{~K}$.

mechanism depicted by Davis, ${ }^{\mathbf{1 1}}$ where it is the support which mediates the second and rate determining step of the reaction, i.e. the activation of the $\mathrm{C}-\mathrm{H}$ bond of the ensuing alkoxide intermediate to form the aldehyde. Considering the $\mathrm{NH}_{3}$ treated CNFs, it was thus not surprising that by increasing the basic site amount (Table 2) we observed an increasing of the catalyst activity in the same order (Fig. 4) even the huge difference between Au/N-CNF $473 \mathrm{~K}$ and Au/N-CNF 673 $\mathrm{K}$ was not fully justified by simply considering the increase of basic sites $[\mathrm{Au} / \mathrm{N}$ CNF $473 \mathrm{~K}$ (TOF $112 \mathrm{~h}^{-1}$ ) < Au/N-CNF $673 \mathrm{~K}$ (TOF $597 \mathrm{~h}^{-1}$ ) < Au/N-CNF 873 $\mathrm{K}\left(\mathrm{TOF} 853 \mathrm{~h}^{-1}\right)$ ]. The positive effect on the catalytic performance in the liquid phase of $\mathrm{NH}_{3}$ treatment has also been observed in the case of Pd supported NPs. ${ }^{22}$ It should be noted, that the different functionalization temperature determined the presence of different surface chemical groups in the samples: at lower temperature $(473 \mathrm{~K})$ prevalent amide-like groups were observed, which were 
transformed at higher temperature into pyridine-like groups. ${ }^{21}$ In the sample treated at higher temperature $(873 \mathrm{~K})$, microcalorimetric measurements also revealed the presence of strong oxygen basic sites similar to those observed in hydrotalcite ${ }^{23}$ and in $\gamma-\mathrm{Al}_{2} \mathrm{O}_{3},{ }^{24}$ along with a majority of weaker basic sites. The amination process produces a gradual increase of the hydrophobic character of the surface by increasing the temperature of the treatment.

Concerning the selectivity of the glycerol oxidation reaction (Scheme 1), Table 4 showed some unexpected results. On the one hand, using catalysts with similar $\mathrm{Au}$ particle size, we were expecting similar selectivity. ${ }^{1,2}$ This did not occur, clearly indicating that some other factors influence the selectivity of the process. Pristine CNTs and CNFs showed different selectivity, CNTs being more selective toward C2 products (glycolate and oxalate) than CNFs (Table 4). In both cases, the oxidative treatment increased the selectivity towards $\mathrm{C} 3$ products (glycerate and tartronate) and did not alter the activity of the catalysts very much (Table 4 and Fig. 3). In the case of $\mathrm{CNF}$, we observed a breakdown of selectivity for $\mathrm{NH}_{3}$ treated samples, but only when the temperature of treatment was over $673 \mathrm{~K}$, i.e. when the catalysts become more active. Indeed, selectivity did not change very much for $\mathrm{Au} / \mathrm{CNF}, \mathrm{Au} /$ $\mathrm{CNF}$ ox and $\mathrm{Au} / \mathrm{N}-\mathrm{CNF} 473 \mathrm{~K}$, with $55-65 \%$ selectivity to glycerate, none to tartronate, $20-27 \%$ selectivity to glycolate and $10-16 \%$ selectivity to formate (Table 4 all the selectivities reported are at $90 \%$ conversion). On the contrary, in the case of $\mathrm{Au} / \mathrm{N}-\mathrm{CNF} 673 \mathrm{~K}$ and $\mathrm{Au} / \mathrm{N}-\mathrm{CNF} 873 \mathrm{~K}$, a decrease of C2-C1 products (glycolate and formate) to $13 \%$ selectivity and 5-6\% selectivity, respectively, was detected. Meanwhile an increase in $\mathrm{C} 3$ products (glycerate and tartronate) to $79-82 \%$ selectivity was observed (Table 4 -all the selectivities reported are at $90 \%$ conversion). This behavior could be possibly explained by the surface properties related to the presence of different chemical groups. Accepting the $\mathrm{H}_{2} \mathrm{O}_{2}$ detected during the reaction as responsible for the $\mathrm{C}-\mathrm{C}$ bond cleavage ${ }^{\mathbf{1 0 , 1 3}}$ and accepting that $\mathrm{H}_{2} \mathrm{O}_{2}$ derives from the $\mathrm{O}_{2}$ reduction by $\mathrm{H}_{2} \mathrm{O}$ adsorbed on the catalyst surface, ${ }^{11}$ we could expect $\mathrm{H}_{2} \mathrm{O}_{2}$ formation to be related to the water adsorption capacity of the support, i.e. its hydrophilicity. The functionalization with $\mathrm{HNO}_{3}$ and the subsequent treatment with $\mathrm{NH}_{3}$ at different temperatures has been shown to increase the hydrophobicity of the surface progressively by increasing the temperature. Thus in our case, the increase of the basicity in $\mathrm{Au} / \mathrm{N}-\mathrm{CNF} 873 \mathrm{~K}$ should be expected to increase the activity by promoting the alcoholate formation and $\mathrm{C}-\mathrm{H}$ bond cleavage, whereas the increase of surface hydrophobicity could lead to an higher selectivity to $\mathrm{C} 3$ by decreasing the $\mathrm{H}_{2} \mathrm{O}_{2}$ formation. However, during the tests, no significant differences in $\mathrm{H}_{2} \mathrm{O}_{2}$ concentration have been revealed. This was not surprising as the basic media could influence the degradation rate of the peroxide. Therefore, to better

Table 4 Glycerol oxidation with Au/CNTs and Au/CNFs under basic conditions ${ }^{a}$

\begin{tabular}{|c|c|c|c|c|c|c|}
\hline \multirow[b]{2}{*}{ Catalyst } & \multirow[b]{2}{*}{$\operatorname{TOF}^{b}\left(\mathrm{~h}^{-1}\right)$} & \multicolumn{5}{|l|}{ Selectivity $^{c}$} \\
\hline & & Glycerate & Tartronate & Glycolate & Oxalate & Formate \\
\hline $\mathrm{Au} / \mathrm{CNTs}$ & 648 & 26 & 7 & 14 & 53 & $<1$ \\
\hline $\mathrm{Au} / \mathrm{CNT}$ ox & 742 & 59 & 11 & 17 & 13 & $<1$ \\
\hline $\mathrm{Au} / \mathrm{CNF}$ & 182 & 55 & 1 & 27 & 0 & 16 \\
\hline $\mathrm{Au} / \mathrm{CNF}$ ox & 186 & 65 & $<1$ & 20 & 0 & 10 \\
\hline $\mathrm{Au} / \mathrm{N}-\mathrm{CNF} 473 \mathrm{~K}$ & 112 & 64 & $<1$ & 22 & 0 & 12 \\
\hline $\mathrm{Au} / \mathrm{N}-\mathrm{CNF} 673 \mathrm{~K}$ & 597 & 66 & 13 & 13 & 0 & 6 \\
\hline $\mathrm{Au} / \mathrm{N}-\mathrm{CNF} 873 \mathrm{~K}$ & 853 & 68 & 14 & 13 & 0 & 5 \\
\hline \multicolumn{7}{|c|}{$\begin{array}{l}{ }^{a} \text { Reaction conditions: in water, glycerol } / \text { metal: } 1000 \mathrm{~mol} \mathrm{~mol}{ }^{-1}, T=323 \mathrm{~K}, \mathrm{pO}_{2}=3 \mathrm{~atm} ., 4 \mathrm{eq} \\
\mathrm{NaOH}^{b} \text { TOF calculated at } 30 \mathrm{~min} \text { on the basis of total metal loaded }{ }^{c} \text { Selectivity at } 90 \% \\
\text { conversion }\end{array}$} \\
\hline
\end{tabular}


Table 5 Base free oxidation of glycerol and $\mathrm{H}_{2} \mathrm{O}_{2}$ detected. $^{a}$

\begin{tabular}{|c|c|c|c|c|c|c|c|}
\hline \multirow[b]{2}{*}{ Catalyst } & \multirow[b]{2}{*}{$\begin{array}{l}\mathrm{TOF}^{b} \\
\left(\mathrm{~h}^{-1}\right)\end{array}$} & \multicolumn{5}{|l|}{ Selectivity $^{c}$} & \multirow[b]{2}{*}{$\begin{array}{l}\mathrm{H}_{2} \mathrm{O}_{2}{ }^{d} \\
\mathrm{mmol} \mathrm{L}^{-1}\end{array}$} \\
\hline & & Glycerate & $\begin{array}{l}\text { Hydroxy } \\
\text { pyruvic }\end{array}$ & Glycolate & Oxalate & Formate & \\
\hline $\mathrm{Au} / \mathrm{CNF}$ & 0.5 & 41 & 17 & 12 & 0 & 30 & 1.5 \\
\hline $\mathrm{Au} / \mathrm{CNF}$ ox & 0.6 & 33 & 26 & 19 & 0 & 22 & 2.0 \\
\hline \multicolumn{8}{|l|}{$473 \mathrm{~K}$} \\
\hline $\begin{array}{l}\mathrm{Au} / \mathrm{N}-\mathrm{CNF} \\
673 \mathrm{~K}\end{array}$ & 3.8 & 66 & 7 & 10 & 0 & 15 & 0.5 \\
\hline $\begin{array}{l}\mathrm{Au} / \mathrm{N}-\mathrm{CNF} \\
873 \mathrm{~K}\end{array}$ & \multicolumn{6}{|c|}{$873 \mathrm{~K}$} & 0.3 \\
\hline $\begin{array}{l}{ }^{a} \text { Reaction co } \\
\text { calculated at } \\
\text { from titratior }\end{array}$ & $\begin{array}{l}\text { dition } \\
\min \\
\text { at isoc }\end{array}$ & $\begin{array}{l}\text { in water, gl } \\
n \text { the basis o } \\
\text { nversion }\end{array}$ & $\begin{array}{l}\text { fcerol } / \text { meta } \\
\text { f total meta } \\
\%) \text {. }\end{array}$ & $\begin{array}{l}500 \mathrm{~mol} \mathrm{~m} \\
\text { loaded. }{ }^{c}\end{array}$ & $\begin{array}{l}\mathrm{l}^{-1}, T= \\
\text { lectivity }\end{array}$ & $\begin{array}{l}3 \mathrm{~K}, \mathrm{pO}_{2}= \\
20 \% \text { conv }\end{array}$ & $\begin{array}{l}3 \text { atm. }{ }^{b} \mathrm{TOF} \\
\text { ersion. }{ }^{d} \mathrm{H}_{2} \mathrm{O}\end{array}$ \\
\hline
\end{tabular}

clarify this point, we carried out some experiments under base-free conditions, as $\mathrm{H}_{2} \mathrm{O}_{2}$ is more stable at neutral-acidic $\mathrm{pH}$. Tests under base-free conditions $(373 \mathrm{~K}$ without any addition of base) showed a higher (even low) activity for Au/N-CNF $873 \mathrm{~K}$, the most basic and hydrophobic catalyst. As under non-basic conditions we expected $\mathrm{H}_{2} \mathrm{O}_{2}$ to degrade more slowly than under basic conditions, ${ }^{13}$ we can use the amount of $\mathrm{C}-\mathrm{C}$ cleavage as a probe of $\mathrm{H}_{2} \mathrm{O}_{2}$ formation. Au/N-CNF 873 $\mathrm{K}$, also under these conditions, produced $\mathrm{C}-\mathrm{C}$ bond cleavage products (glycolate and formate) in a smaller amount than $\mathrm{Au} / \mathrm{CNF} 473 \mathrm{~K}$ (Table 5). $\mathrm{H}_{2} \mathrm{O}_{2}$ quantification by titration confirmed a lesser concentration in the case of Au/N-CNF $873 \mathrm{~K}$ (0.3 mmol L $\mathrm{m}^{-1}$ for Au/N-CNF $873 \mathrm{~K}$ vs $2.0 \mathrm{mmol} \mathrm{L}^{-1}$ for Au/CNFox - Table 5). Moreover blank experiments highlighted the same degradation rate for $\mathrm{H}_{2} \mathrm{O}_{2}$ in the presence of both catalysts (Fig. 5). These results seem to confirm our hypothesis that the hydrophobic nature of N-CNF $873 \mathrm{~K}$ contributed to the decrease in peroxide formation i.e. an increase in $\mathrm{C} 3$-product selectivity. More accurate kinetic investigations are being carried out in order to confirm this finding.

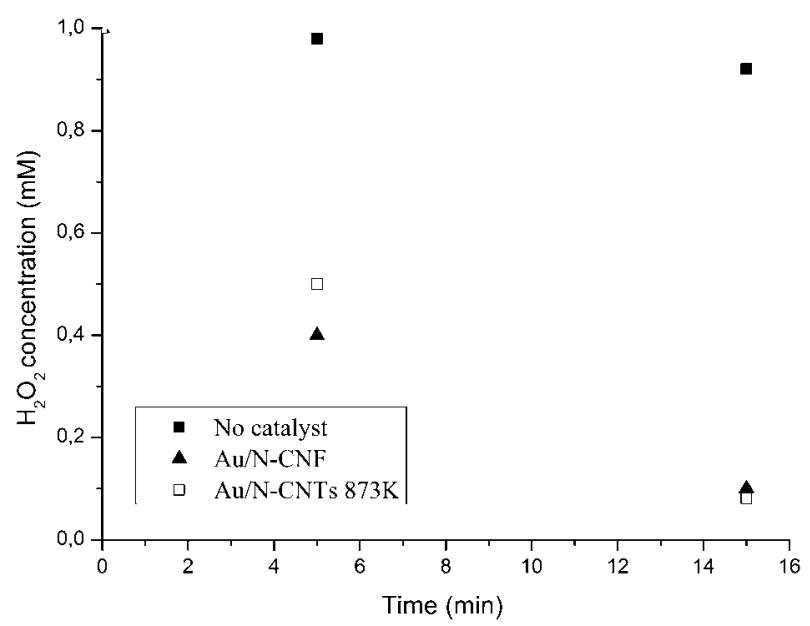

Fig. $5 \mathrm{H}_{2} \mathrm{O}_{2}$ degradation profile for $\mathrm{Au} / \mathrm{CNF}$ and $\mathrm{Au} / \mathrm{CNF} 873 \mathrm{~K}$ under acidic conditions $(\mathrm{pH}$ $2.5)$. 
Table 6 Benzyl alcohol oxidation ${ }^{a}$

\begin{tabular}{|c|c|c|c|c|c|}
\hline \multirow[b]{2}{*}{ Catalyst } & \multirow[b]{2}{*}{$\operatorname{TOF}^{b}\left(\mathrm{~h}^{-1}\right)$} & \multicolumn{4}{|l|}{ Selectivity $^{c}$} \\
\hline & & Benzaldehyde & Benzoic acid & Benzyl benzoate & Toluene \\
\hline $\mathrm{Au} / \mathrm{CNF}$ & 7 & $92 *$ & - & - & 8 \\
\hline $\mathrm{Au} / \mathrm{N}-\mathrm{CNF} 473 \mathrm{~K}$ & 65 & 93 & 2 & - & 5 \\
\hline $\mathrm{Au} / \mathrm{N}-\mathrm{CNF} 673 \mathrm{~K}$ & 88 & 88 & 5 & 3 & 3 \\
\hline $\mathrm{Au} / \mathrm{N}-\mathrm{CNF} 873 \mathrm{~K}$ & 102 & 85 & 8 & 3 & 3 \\
\hline
\end{tabular}

Moreover, under base-free experimental conditions, it was shown that secondary alcohol can also be oxidized and hydroxypyruvic acid formed, highlighting for these two catalysts a different selectivity towards primary and secondary $\mathrm{OH}$. Au/CNF $473 \mathrm{~K}$ appeared the most reactive and, considering that selectivity to glyceric acid is quite low, we could conclude that the oxidation of secondary alcohol is consecutive and most probably depends on a different adsorption mode.

Additional tests have also been performed using benzyl alcohol. The reaction was carried out in water without the addition of a base at $333 \mathrm{~K}$. The increase of activity with the increase of basicity of the support could be expected, as well as the increase of benzoic acid, the formation of which is known to be favored by a basic environment $^{23}$ (Table 6). It should be noted, however, that, as in the case of glycerol, the consecutive reaction producing benzoic acid from benzaldehyde is favored by an increase in hydrophobicity of the support i.e. N-CNF $673 \mathrm{~K}$ and N-CNF $873 \mathrm{~K}$

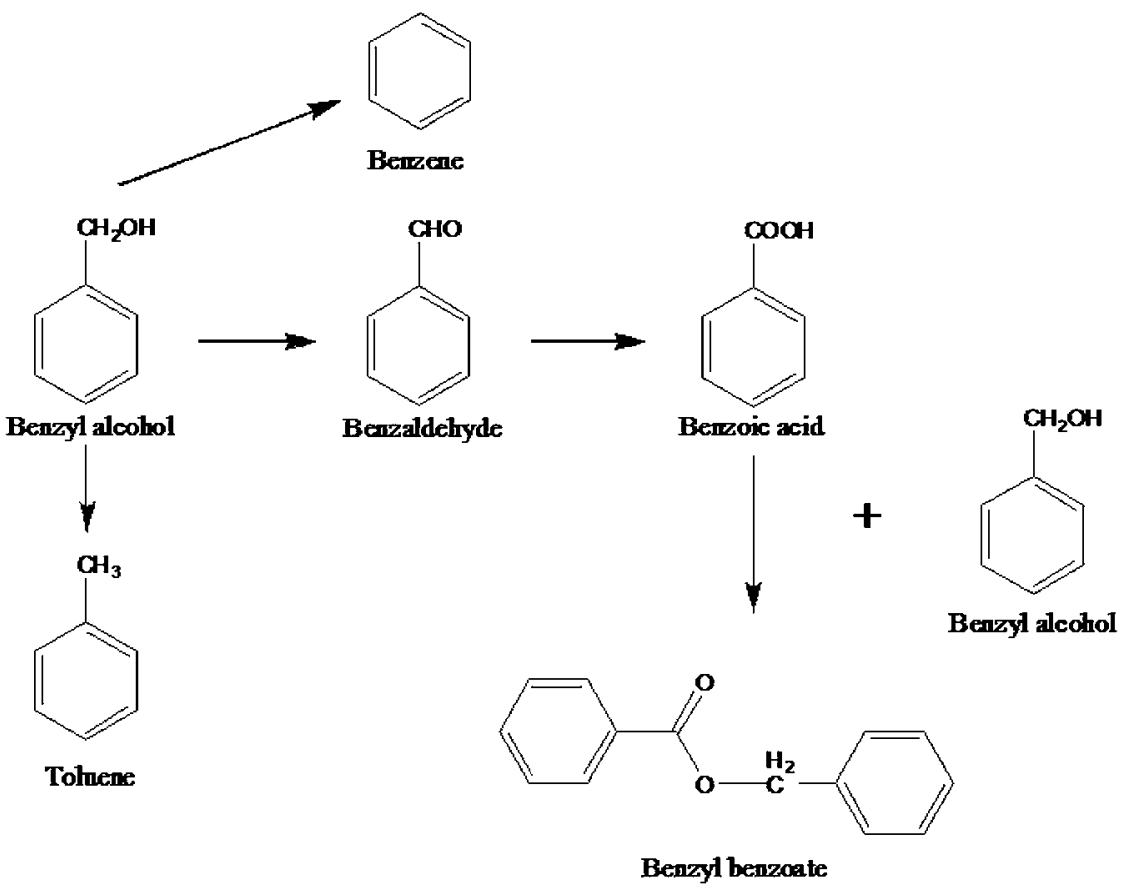

Scheme 2 Reaction scheme for benzyl alcohol oxidation. 
(Scheme 2 - Table 6). We also observed a different distribution in the minor products of the reaction, namely benzyl benzoate and toluene. Benzyl benzoate could be considered formed through a consecutive reaction, ${ }^{7}$ but the formation of toluene follows a different pathway, probably through dehydrogenation ${ }^{5}$ (Scheme 2).

\section{Conclusions}

Alcohol oxidation in the liquid phase has been investigated, paying particular attention to the selectivity of the process and particularly to the role that the support can play. Reactions performed in water are of interest, because of the application to water soluble alcohol and particularly to glycerol, an important renewable feedstock. Commercially available CNTs and CNFs have been used as starting materials, because they did not present a relevant microporosity that could lead to diffusional limitation during liquid phase oxidation. Functionalization of CNTs and CNFs has been performed using the procedure set up by Arrigo et al. ${ }^{21}$ which produced fully characterized supports. Preformed gold sol has been immobilized on the supports, yielding Au catalysts with almost the same particle size, but showing different catalytic activity/selectivity as a function of the supporting material. In the glycerol selective oxidation it has been shown that the activity increased with the basicity of CNFs, whereas the selectivity appeared most related to the type of surface groups. Indeed, basic and hydrophobic surfaces enhanced the selectivity to $\mathrm{C} 3$ products, whereas more hydrophilic surfaces increased the $\mathrm{C}-\mathrm{C}$ bond cleavage products. This behavior is possibly correlated to a higher concentration of native $\mathrm{H}_{2} \mathrm{O}_{2}$ detected in the presence of hydrophilic support.

\section{Acknowledgements}

Fondazione Cariplo is gratefully acknowledged for financial support

\section{References}

1 S. Carrettin, P. McMorn, P. Johnston, K. Griffin, C. J. Kiely and G. J. Hutchings, Phys. Chem. Chem. Phys., 2003, 5, 1329.

2 F. Porta and L. Prati, J. Catal., 2004, 224, 397.

3 S. Demirel-Gulen, M. Lucas and P. Claus, Catal. Today, 2005, 102-103, 166.

4 W. Fang, J. Chen, Q. Zhang, W. Deng and Y. Wang, Chem.-Eur. J., 2011, 17, 1247.

5 M. Boronat, A. Corma, F. Illas, J. Radilla, T. Ródenas and M. J. Sabater, J. Catal., 2011, 278, 50 .

6 T. Ishida, M. Nagaoka, T. Akita and M. Haruta, Chem.-Eur. J., 2008, 19, 8456.

7 S. Meenakshisundaram, E. Nowicka, P. J. Miedziak, G. L. Brett, R. L. Jenkins, N. Dimitratos, S. H. Taylor, D. W. Knight, D. Bethell and G. J. Hutchings, Faraday Discuss., 2010, 145, 341.

8 C. H. Zhou, J. N. Beltramini, Y. X. Fan and G. Q. Lu, Chem. Soc. Rev., 2008, 37, 527.

9 A. Corma, S. Iborra and A. Velty, Chem. Rev., 2007, 107, 2411.

10 W. C. Ketchie, Y. Fang, M. S. Wong, M. Murayama and R. J. Davis, J. Catal., 2007, 250, 94-101.

11 B. N. Zope, D. D. Hibbits, M. Neurock and R. J. Davis, Science, 2010, 330, 74.

12 N. Dimitratos, A. Villa, D. Wang, F. Porta, D. Su and L. Prati, J. Catal., 2006, 244, 113.

13 L. Prati, P. Spontoni and A. Gaiassi, Top. Catal., 2009, 52, 288.

14 A. Villa, G. M. Veith and L. Prati, Angew. Chem., Int. Ed., 2010, 49, 4499.

15 R. Arrigo, M. Hävecker, R. Schlögl and D. S. Su, Chem. Commun., 2008, 4891.

16 L. Prati and G. Martra, Gold Bull., 1999, 32, 96.

17 A. Villa, A. Gaiassi, I. Rossetti, C. L. Bianchi, K. van Benthem, G. M. Veith and L. Prati, J. Catal., 2010, 275, 108.

18 A. Abad, A. Corma and H. Garcia, Chem.-Eur. J., 2008, 14, 212.

19 C. Lemire, R. Meyer, S. Shaikhutdinov and H.-J. Freund, Angew. Chem., Int. Ed., 2004, 43, 118.

20 J. P. Tessonnier, D. Rosenthal, T. W. Hansen, C. Hess, M. E. Schuster, R. Blume, F. Girgsdies, N. Pfaender, O. Timpe, D. S. Su and R. Schloegl, Carbon, 2009, 47, 1779. 
21 R. Arrigo, M. Haevecker, S. Wrabetz, R. Blume, M. Lerch, J. McGregor, E. P. J. Parrott, J. A. Zeitler, L. F. Gladden, A. Knop-Gericke, R. Schloegl and D. Su, J. Am. Chem. Soc., 2010, 132, 9616.

22 A. Villa, D. Wang, P. Spontoni, R. Arrigo, D. Su and L. Prati, Catal. Today, 2010, 157, 89.

23 W. Winter, X. Xia, B. P. C Hereijgers, J. H Bitter, A. J. van Dillen, M. Muhler and K. P. de Jong, J. Phys. Chem. B, 2006, 110(18), 9211.

24 J. Shen, R. D. Cortright, Y. Chen and J. A. Dumesic, Catal. Lett., 1994, 26(3-4), 247. 